\title{
MAFK Polymorphisms Located in 3'-UTR are Associated with Severity of Atrophy and CDKN2A Methylation Status in the Gastric Mucosa
}

\author{
Tasuku Hayashi,, Tomoyuki Shibata, ${ }^{2}$ Masakatsu Nakamura, ${ }^{1}$ Naoko Sakurai, ${ }^{1}$ Hikaru Takano, \\ Masafumi Ota, ${ }^{1}$ Tomoe Nomura-Horita, ${ }^{1}$ Ranji Hayashi, ${ }^{1}$ Takeo Shimasaki, ${ }^{1}$ Toshimi Ostuka, \\ Tomomitsu Tahara, ${ }^{3}$ and Tomiyasu Arisawa ${ }^{1}$
}

Objective: This study was designed to clarify the association of the MAFK polymorphisms (rs4268033, rs3735656, and rs 10226620) with the degree of gastric mucosal atrophy and CDKN2A CpG methylation status. Methods: A total of 491 subjects were enrolled in this study. Genotypes and methylation status were determined by polymerase chain reaction (PCR)-single-stranded conformation polymorphism and methylation-specific PCR (Fujita Health University, HM18-094).

Methods: A total of 491 subjects were enrolled in this study. Genotypes and methylation status were determined by polymerase chain reaction (PCR)-single-stranded conformation polymorphism and methylation-specific PCR (Fujita Health University, HM18-094).

Results: Both rs3735656 and rs10226620, located in the 3'-UTR of MAFK, were significantly associated with the severity of gastric mucosal atrophy using a dominant genetic model (odds ratio [OR], 2.10; $p=0.0012$, and OR, 1.98; $p=0.0027$, respectively). Under a recessive genetic model, no significant association was found between three polymorphisms and gastric mucosal atrophy. The serum pepsinogen I/II ratio was significantly lower in subjects with minor alleles of rs 3735656 and rs 10226620 than in subjects that were homozygous WT ( $p=0.018$ and 0.013 , respectively). In a subgroup including 400 of the 491 subjects, the CpG of $p 14^{A R F}$ and $p 16^{I N K 4 a}$ were methylated in 132 and 112 subjects, respectively. Fifty subjects had both $\mathrm{CpG}$ methylations and 206 subjects had neither methylation. When comparing the groups with both and neither methylations, there were no significant associations between any of the three polymorphisms and $C D K N 2 A$ methylation under a dominant genetic model. However, all polymorphisms investigated in this study (rs4268033, rs3735656, and rs10226620) were significantly associated with $C D K N 2 A$ methylation in a recessive genetic model (OR, 3.58; $p=0.0071$, OR, 4.49; $p=0.0004$, and $\mathrm{OR}, 3.45 ; p=0.0027$, respectively).

Conclusions: Our results indicate that possession of either of the minor allele $M A F K$ polymorphisms that are located in the $3^{\prime}$-UTR increase the risk of severe gastric mucosal atrophy; furthermore CDKN2A CpG methylation may develop in subjects who are homozygous for the minor alleles of the these MAFK 3'-UTR SNPs.

Keywords: $M A F K$, polymorphisms, gastric mucosal atrophy, $C D K N 2 A, \mathrm{CpG}$ hypermethylation

\section{Introduction}

$\mathbf{I}^{\mathrm{N}}$ N THE FISCAL year 2018, an estimated 1 million people were diagnosed with gastric cancer worldwide, and 783,000 people died from the disease (Bray et al., 2018). In Japan alone, $\sim 29,000$ people died of gastric cancer in the fiscal year 2018, suggesting that it is a disease of global concern. Previous studies have shown that Helicobacter pylori infection is involved in gastric cancer (Plummer et al., 2016), which develops through the atrophic gastritis triggered by the infection (Watanabe et al., 1997; Ozasa et al., 1999). In addition, severe atrophy, corpus-dominant gastritis, and intestinal metaplasia have been reported as risk factors for the development of gastric cancer (Uemura et al., 2001).

DNA methylation is closely associated with gene inactivation; correspondingly, $\mathrm{CpG}$ island hypermethylation (CIHM) of tumor suppressor genes has been identified in several human malignancies (Jones and Baylin, 2002; Li and Chen, 2013). Such epigenetic alterations have been observed in gastric cancer (Tan and Yeoh, 2015). This aberrant methylation has previously been observed in the precancerous nontumorous mucosa, suggesting an association with inflammation caused by $H$. pylori infection (Niwa et al., 2010). Both $p 14^{A R F}$ and $p 16^{I N K 4 a}$, which are tumor suppressor

\footnotetext{
${ }^{1}$ Department of Gastroenterology, Kanazawa Medical University, Uchinada-machi, Japan.

${ }^{2}$ Department of Gastroenterology, Fujita Health University, Kutsukake-cho, Japan.

${ }^{3}$ Department of Gastroenterology and Hepatology, Kansai Medical University, Hirakata, Japan.
} 
genes produced from the alternative splicing of $C D K N 2 A$, are relatively frequently methylated (Maekita et al., 2006; Tahara et al., 2007).

Oxidative stress is one of the most essential factors affecting inflammation in $H$. pylori infection (Naito and Yoshikawa, 2002). Nuclear factor-erythroid 2-related factor 2 (Nrf2) plays an important role in eliminating reactive oxygen species (ROS) produced by oxidative stress (Ishii et al., 2000). Nrf2 alone was demonstrated to be unable to induce antioxidant enzymes such as heme oxygenase-1 (HO-1) and peroxiredoxin 1; moreover, it exerted transcriptional activity by forming a heterodimer with small musculoaponeurotic fibrosarcoma (Maf; Itoh et al., 1997). We have previously found a genetic polymorphism of NFE2L2 that encodes Nrf2 is associated with the degree of gastric mucosal atrophy and the $\mathrm{CpG}$ methylation of CDKN2A (Arisawa et al., 2007, 2008). We also clarified that there is a significant association between a genetic polymorphism of $M A F K$ that codes for MafK, a small Maf, and the susceptibility of ulcerative colitis (Arisawa et al., 2017).

This study was aimed at elucidating whether a genetic polymorphism of $M A F K$ is associated with gastric mucosal atrophy, a precancerous condition, and aberrant $C D K N 2 A$ methylation.

\section{Methods}

\section{Clinical samples}

The samples were selected at random among subjects attending the Endoscopic Center of Fujita Health University Hospital and registered from January 2006 to December 2012. All study subjects underwent upper gastrointestinal endoscopy as a part of a health checkup, as a secondary examination following barium X-ray gastrography, or due to symptoms of abdominal discomfort. Subjects with severe systemic diseases or malignancies of the stomach or other organs, as well as those with a history of abdominal surgery or $H$. pylori eradication were excluded. Among all registered subjects, we randomly selected 400 subjects from 514 subjects stocked in our database with the assessment of histological degree of atrophy and CIHM status of CDKN2A in the antral mucosa, and 200 subjects with the assessment of histological degree of gastric mucosal atrophy and the measurement of serum pepsinogen (PG) I and II levels; consequently, the study population comprised 491 subjects, because 109 subjects were overlapped. In 1000 genomes database, the frequency of rs4268033 minor allele was $\sim 40 \%$. We assume that a $30 \%$ decrease in the prevalence of an allelic frequency would be of clinical relevance. Assuming an alpha value $=0.05$ and a power $=0.80$, at least 243 subjects in each group would be sufficient to identify a clinically relevant difference. Accordingly, we thought that this sample size could be evaluated. The protocol for this study was approved by the Ethics Committee of Fujita Health University (HM18-094), and written consent was obtained in all cases.

At the time of endoscopy, a biopsy was performed from the antrum. A portion of the biopsy tissue was frozen and stored at $-80^{\circ} \mathrm{C}$ until used for the detection of methylation. Meanwhile, another portion of the biopsy tissue was hematoxylin eosin stained and provided to the pathologist, who had not been informed of the background information, for grading the extent of histological gastritis according to the updated
Sydney system (Dixon et al., 1996). The subjects were divided into two groups based on the degree of histological atrophy, as follows:

NA (nonatrophy, $n=288$ ) group: atrophy score $=0$ or 1 and metaplasia score $=0$. AG (atrophic gastritis, $n=203$ ) group: remaining subjects. Serum PG I and PG II levels were measured in 200 subjects through a radioimmunoassay. When any one of the results of the rapid urease test, urea breath test, histological test, or serum antibody test was positive, the patient was determined to have $H$. pylori infection.

\section{Selection of single nucleotide polymorphisms of MAFK}

In $M A F K$ genome region, there are two linkage disequilibrium blocks above 0.05 of Hardy-Weinberg equilibrium (HWE) $p$-value and above 0.05 of minor allele frequency. At first, we selected rs3735656, located in $3^{\prime}$-UTR, among two Tag single nucleotide polymorphisms (SNPs) of each block. Next, within 2000 bp around $M A F K$, two large linkage blocks are found with the same conditions described above. Then, we selected a Tag SNP (rs4268033), which is not in linkage disequilibrium with rs3735656. Finally, the other SNP rs10226620, which is located in $3^{\prime}$-UTR where several microRNA bind to, was also selected.

\section{Genotyping}

Genomic DNA was extracted from a part of the cryopreserved specimens using proteinase K. In some subjects, genomic DNA was extracted from the peripheral blood collected at the time of endoscopy and stored at $-80^{\circ} \mathrm{C}$. Genotyping was performed by the polymerase chain reaction (PCR)-single-stranded conformation polymorphism (SSCP), which we previously reported (Arisawa et al., 2017). The used primer sets are shown in Table 1. PCR was performed using EX Taq HS (Takara Bio, Shiga, Japan) with the addition of $0.1 \mu \mathrm{g}$ of genetic DNA to $20 \mu \mathrm{L}$ of a buffer and under the following conditions: denaturing at $95^{\circ} \mathrm{C}$ for $3 \mathrm{~min}$, followed by 35 cycles of $15 \mathrm{~s}$ at $96^{\circ} \mathrm{C}, 30 \mathrm{~s}$ at $60^{\circ} \mathrm{C}$, and $30 \mathrm{~s}$ at $72^{\circ} \mathrm{C}$; and a final extension for $5 \mathrm{~min}$ at $72^{\circ} \mathrm{C}$ for $\mathrm{rs} 4268033$ and rs10226620. The same PCR conditions were used for rs 3735656 , except the 35 repeating cycles were replaced by those of $15 \mathrm{~s}$ at $96^{\circ} \mathrm{C}$ and $40 \mathrm{~s}$ at $54^{\circ} \mathrm{C}$. Then, $2 \mu \mathrm{L}$ of the PCR product was treated in $10 \mu \mathrm{L}$ of formamide for $5 \mathrm{~min}$ at $90^{\circ} \mathrm{C}$ and denatured to a single strand. The SSCP analysis was performed using the Gene Phor DNA separation system with the Gene Gel Excel 12.5/24 kit (GE Health Care BioSciences AB, Stockholm, Sweden) at a constant temperature of $18^{\circ} \mathrm{C}$, and the denatured bands were detected with a DNA silver staining kit (GE Health Care Bio-Sciences AB).

\section{Bisulfite reaction and methylation-specific PCR methods}

To detect DNA methylation, genomic DNA extracted from the stocked frozen biopsy tissues was treated with sodium bisulfite using the BislFast DNA Modification Kit for Methylated DNA Detection (Toyobo, Osaka, Japan). The methylation-specific PCR was performed as previously described (Tahara et al., 2007, 2009). The used primer sets are shown in Table 1. Using EX Taq HS (Takara Bio), the PCR was performed with the addition of $0.1 \mu \mathrm{g}$ of bisulfitemodified DNA in $20 \mu \mathrm{L}$ of a buffer. The PCR conditions were 
Table 1. Primer Sets Used in This Study

\begin{tabular}{lll}
\hline & \multicolumn{1}{c}{ Forward } & Reverse \\
\hline $\begin{array}{l}\text { Primer sets for MAFK } \\
\text { rs4268033 }\end{array}$ & \\
rs3735656 & $5^{\prime}$-taatcccaactcgcagcatctgtgt-3' & $5^{\prime}$-ggtctgacttagctggggaaagtgc-3' \\
rs10226620 & $5^{\prime}$-atctcagcggacacaggcagga-3' & $5^{\prime}$-ctgcactgaccacagttggtgagaa-3' \\
Primer sets for MSP & $5^{\prime}$-gtcctcctgtgactggggtctct-3' & $5^{\prime}$-aggcaccacttgcaggtcttatgt-3' \\
p14 unmethylated & & \\
p14 methylated & $5^{\prime}$-gagtttggtttggaggtgg-3' & $5^{\prime}$-aaccacaacaacaaacacccct-3' \\
p16 unmethylated & $5^{\prime}$-tgagtttggtttggaggtgg-3' & $5^{\prime}$-aaaaccacaacgacgaacg-3' \\
p16 methylated & $5^{\prime}$-ttattagagggtggggtggattgt-3' & $5^{\prime}$-caaccccaaaccacaaccataa-3' \\
\hline
\end{tabular}

MSP, methylation-specific polymerase chain reaction.

those previously reported (Tahara et al., 2007, 2009). Electrophoresis using $2.5 \%$ agarose gel was performed with $10 \mu \mathrm{L}$ of the PCR products, which were stained with ethidium bromide and visualized by UV illumination. The presence of CIHM was determined when the signal of the positively methylated band was stronger compared with the size maker (10 ng/ $\mu \mathrm{L}$ : $100 \mathrm{bp}$ DNA Ladder; Takara Bio), regardless of the presence of unmethylated bands. The validity of judgment for CIHM status was confirmed in our previous study (Tahara et al., 2011). In addition, in each experiment, the validity of the results was confirmed using both negative control (DNA from the peripheral blood of a young individual without $H$. pylori infection) and positive control (DNA, used negative control, treated with SssI methylase, New England BioLabs, Inc., Beverly, MA, USA). Samples giving faint positive signals were analyzed a further two times and only those samples with consistent positive methylation band were considered CIHM.

\section{Statistical analysis}

Deviations from HWE were confirmed by the $\chi^{2}$ test. The mean age was expressed as the mean \pm standard deviation and assessed by the Student's $t$-test. The $H$. pylori infection rate and sex ratio were assessed by Fisher's exact test. The genotype distributions and allele frequencies were also assessed by Fisher's exact test. The odds ratios and $95 \%$ confidence intervals for the strength of genotype involvement in CIHM were calculated using a logistic regression analysis adjusted for sex $($ male $=1)$, age, and the presence of $H$. pylori infection (infected $=1$ ). The serum PG I/II ratio was assessed by the Student's $t$-test. All analyses were considered significant when $p<0.05$. Stata software (version 13; StataCorp LP, College Station, TX, USA) was used for the statistical processing.

\section{Results}

The clinical background and genotype distribution of the 491 subjects are shown in Table 2. The distributions of the $M A F K$ polymorphisms rs4268033, rs3735656, and rs 10226620 were all in HWE ( $p=0.91,0.76$, and 0.09 , respectively). There were 288 subjects in the NA group and 203 in the AG group. Compared with the NA group, the mean age, sex ratio (males to females), and $H$. pylori infection rate were significantly higher in the AG group. There was no significant

Table 2. Subject Characteristics and Genotype Frequencies

\begin{tabular}{|c|c|c|c|c|}
\hline & Total & NA group & $A G$ group & $\mathrm{p}^{\mathrm{a}}$ \\
\hline No. of subjects & 491 & 288 & 203 & \\
\hline Mean age $\pm S D$ & $59.7 \pm 13.3$ & $57.5 \pm 13.8$ & $62.9 \pm 11.9$ & $<0.0001$ \\
\hline Male:female & 290:201 & $152: 136$ & $138: 65$ & 0.0008 \\
\hline \multicolumn{5}{|l|}{ rs $4268033 \mathrm{G}>\mathrm{A}$} \\
\hline GG & 257 & 161 & 96 & NS \\
\hline GA & 196 & 104 & 92 & \\
\hline AA & 38 & 23 & 15 & NS \\
\hline A allele frequency & $27.7 \%$ & $26.0 \%$ & $30.0 \%$ & NS \\
\hline \multicolumn{5}{|l|}{$\mathrm{rs} 3735656 \mathrm{~T}>\mathrm{C}$} \\
\hline TT & 229 & 155 & 74 & 0.0002 \\
\hline $\mathrm{TC}$ & 210 & 107 & 103 & \\
\hline $\mathrm{CC}$ & 52 & 26 & 26 & NS \\
\hline $\mathrm{C}$ allele frequency & $32.0 \%$ & $27.6 \%$ & $38.2 \%$ & 0.0005 \\
\hline \multicolumn{5}{|l|}{$\mathrm{rs} 10226620 \mathrm{C}>\mathrm{T}$} \\
\hline $\mathrm{CC}$ & 241 & 160 & 81 & 0.0007 \\
\hline $\mathrm{CT}$ & 194 & 96 & 98 & \\
\hline TT & 56 & 32 & 24 & NS \\
\hline $\mathrm{T}$ allele frequency & $31.2 \%$ & $27.8 \%$ & $36.0 \%$ & 0.0078 \\
\hline
\end{tabular}

${ }^{a} \mathrm{NA}$ group versus AG group.

AG, atrophic gastritis; NA, nonatrophy; NS, not significant; SD, standard deviation. 
Table 3. Association Between MAFK Polymorphisms and Gastric Mucosal Atrophy

\begin{tabular}{|c|c|c|c|c|c|}
\hline & \multicolumn{3}{|c|}{ Genotype } & OR $(95 \%$ CI $) ; \mathrm{p}$ & OR $(95 \%$ CI); $\mathrm{p}$ \\
\hline $\begin{array}{l}\text { rs4268033 G > A } \\
\text { NA group }(n=288) \\
\text { AG group }(n=203)\end{array}$ & $\begin{array}{r}\text { GG } \\
161 \\
96\end{array}$ & $\begin{array}{r}\text { GA } \\
104 \\
92\end{array}$ & $\begin{array}{l}\text { AA } \\
23 \\
15\end{array}$ & $\begin{array}{l}\text { GG versus GA + AA } \\
\text { Reference } \\
1.50(0.966-2.34) ; 0.071\end{array}$ & $\begin{array}{l}\text { GG + GA versus AA } \\
\text { Reference } \\
1.34(0.606-2.96) ; 0.47\end{array}$ \\
\hline $\begin{array}{l}\text { rs3735656 T >C } \\
\text { NA group }(n=288) \\
\text { AG group }(n=203)\end{array}$ & $\begin{array}{c}\text { TT } \\
155 \\
74\end{array}$ & $\begin{array}{l}\text { TC } \\
107 \\
103\end{array}$ & $\begin{array}{l}\text { CC } \\
26 \\
26\end{array}$ & $\begin{array}{l}\text { TT versus TC }+\mathrm{CC} \\
\text { Reference } \\
2.10(1.34-3.29) ; 0.0012\end{array}$ & $\begin{array}{l}\mathrm{TT}+\mathrm{TC} \text { versus CC } \\
\text { Reference } \\
0.752(0.379-1.49) ; 0.42\end{array}$ \\
\hline $\begin{array}{l}\text { rs10226620 C > T } \\
\text { NA group }(n=288) \\
\text { AG group }(n=203)\end{array}$ & $\begin{array}{r}\mathrm{CC} \\
160 \\
81\end{array}$ & $\begin{array}{r}\text { CT } \\
96 \\
98\end{array}$ & $\begin{array}{l}\text { TT } \\
32 \\
24\end{array}$ & $\begin{array}{l}\mathrm{CC} \text { versus } \mathrm{CT}+\mathrm{TT} \\
\text { Reference } \\
1.98(1.27-3.09) ; 0.0027\end{array}$ & $\begin{array}{l}\mathrm{CC}+\mathrm{CT} \text { versus } \mathrm{TT} \\
\text { Reference } \\
1.10(0.563-2.14) ; 0.78\end{array}$ \\
\hline
\end{tabular}

By logistic regression analysis after adjustment for age, gender (male =1), and Helicobacter pylori infection status (infected =1). CI, $95 \%$ confidence interval; OR, odds ratio.

difference in the distribution of the rs4268033 polymorphism between the AG and NA groups. Conversely, for the rs3735656 and rs10226620 polymorphisms, the wild homozygous frequencies were significantly lower and the minor allele frequencies were significantly higher in the AG group compared with the NA group.

The association of minor alleles of $M A F K$ gene polymorphisms with gastric mucosal atrophy was examined in a regression analysis adjusted for sex, age, and $H$. pylori infection status (Table 3). In a dominant genetic model, carrying the minor allele of rs4268033 showed a tendency to be associated with the degree of gastric mucosal atrophy, but this association was not significant. By contrast, carrying the minor alleles of rs3735656 and rs10226620 displayed significant positive associations in the dominant genetic model.

The serum PG levels of 200 of the 491 enrolled subjects were evaluated. A comparison of the serum PG I/II ratios in the groups with wild homozygous and minor allele carriers for the $M A F K$ gene polymorphisms is shown in Figure 1. No significant difference in the serum PG I/II ratio was found between the subjects with wild homozygous alleles and those with minor alleles for the rs4268033 polymorphism; conversely, for the rs3735656 and rs10226620 polymorphisms, the serum PG I/II ratios were significantly higher in the subjects with the wild homozygous alleles.
The clinical background of the 400 subjects who were evaluated for the degree of $\mathrm{CpG}$ methylation of $C D K N 2 A$ is shown in Table 4. The distributions of the genotypes of rs4268033, rs3735656, and rs10226620 all met HWE $(p=0.36$, 0.67 , and 0.91 , respectively). CIHM of $p 14^{A R F}$ and $p 16^{I N K 4 a}$ was observed in 132 and 112 of the 400 subjects, respectively. The subjects with genes corresponding to either methylation had a higher mean age and $H$. pylori infection rate, and more of those subjects were classified in the AG group. A total of 50 and 206 subjects had CIHM of both genes and neither of the genes, respectively. The mean age, $H$. pylori infection rate, and AG/NA ratio were significantly higher in the both-methylated group than in the neither-methylated group (Table 4). The ratios of minor allele homozygosity for the three polymorphisms were significantly higher in bothmethylated group compared with neither-methylated group. In addition, the minor allele frequencies of rs3735656 and rs10226620 were also higher in the both-methylated group.

For the $M A F K$ polymorphism rs4268033, we found that the frequency of minor allele homozygosity showed a tendency, although nonsignificant, to be positively associated with $p 14^{A R F}$ and $p 16^{I N K 4 a}$ methylations in a recessive genetic model (Table 5). The trend in the association was significant when comparing the both-methylated and neither-methylated groups.
FIG. 1. Comparison of serum PG I/II ratio among MAFK genotypes. There is no significant difference between wild homozygous and minor allele carriers of rs4268033 $(3.85 \pm 3.05$ vs. $4.22 \pm 3.41)$. Whereas, of both rs 3735656 and rs10226620, serum PG I/II ratio was significantly lower in minor allele carriers than in wild homozygous $(3.76 \pm 3.10$ vs. $4.36 \pm 3.26$ and $3.73 \pm 3.18$ vs. $4.37 \pm 3.15$, respectively). PG, pepsinogen.

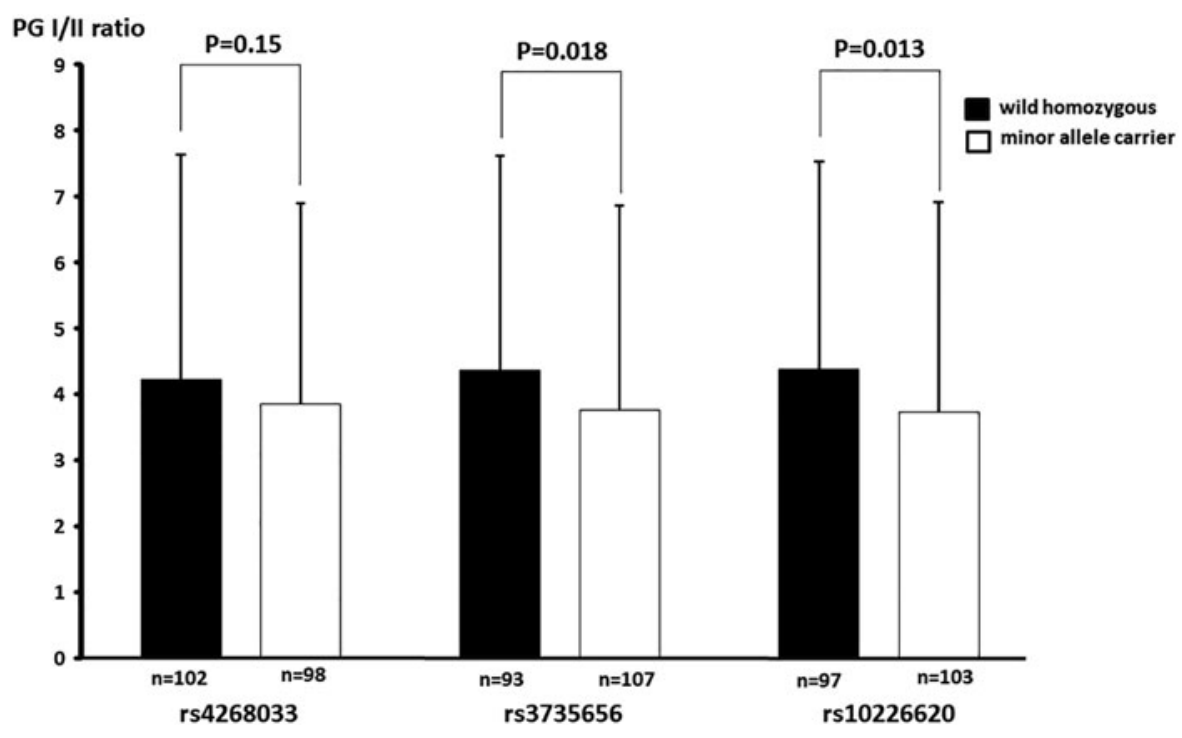


Table 4. Characteristics and Prevalence of Polymorphisms and Methylation Status

\begin{tabular}{|c|c|c|c|c|c|c|}
\hline & Overall & $p 14^{\mathrm{ARF}}-M$ & $p 16^{\mathrm{INK} 4 \mathrm{a}}-M$ & $\begin{array}{c}\text { Both } \\
\text { methylated }\end{array}$ & $\begin{array}{c}\text { Neither } \\
\text { methylated }\end{array}$ & $\mathrm{p}^{\mathrm{a}}$ \\
\hline The no. of subjects & 400 & 132 & 112 & 50 & 206 & \\
\hline Mean age $\pm S D$ & $60.2 \pm 13.6$ & $62.8 \pm 13.6$ & $61.5 \pm 11.9$ & $63.8 \pm 12.3$ & $58.7 \pm 13.9$ & 0.018 \\
\hline Male:female & $230: 170$ & $69: 53$ & $61: 51$ & $25: 25$ & $125: 81$ & NS \\
\hline Helicobacter pylori-positive ratio & $239 / 400$ & $89 / 132$ & $88 / 112$ & $39 / 50$ & $101 / 206$ & 0.0002 \\
\hline \multicolumn{7}{|l|}{ rs $4268033 \mathrm{G}>\mathrm{A}$} \\
\hline GG & 181 & 57 & 53 & 23 & 94 & NS \\
\hline GA & 183 & 58 & 44 & 17 & 98 & \\
\hline AA & 36 & 17 & 15 & 10 & 14 & 0.016 \\
\hline A allele frequency & $31.9 \%$ & $34.8 \%$ & $33.0 \%$ & $37.0 \%$ & $30.6 \%$ & NS \\
\hline \multicolumn{7}{|l|}{$\mathrm{rs} 3735656 \mathrm{~T}>\mathrm{C}$} \\
\hline $\mathrm{TT}$ & 157 & 51 & 44 & 18 & 80 & NS \\
\hline $\mathrm{TC}$ & 193 & 57 & 44 & 17 & 109 & \\
\hline $\mathrm{CC}$ & 50 & 24 & 24 & 15 & 17 & 0.0001 \\
\hline $\mathrm{C}$ allele frequency & $36.6 \%$ & $39.8 \%$ & $50.0 \%$ & $47.0 \%$ & $34.7 \%$ & 0.028 \\
\hline \multicolumn{7}{|l|}{$\mathrm{rs} 10226620 \mathrm{C}>\mathrm{T}$} \\
\hline $\mathrm{CC}$ & 164 & 51 & 44 & 18 & 87 & NS \\
\hline CT & 183 & 58 & 44 & 17 & 98 & \\
\hline TT & 53 & 23 & 24 & 15 & 21 & 0.0010 \\
\hline $\mathrm{T}$ allele frequency & $36.1 \%$ & $39.4 \%$ & $50.0 \%$ & $47.0 \%$ & $34.0 \%$ & 0.020 \\
\hline
\end{tabular}

${ }^{a}$ Both methylated versus neither methylated.

M, methylated.

For the rs3735656, we found that the frequency of minor allele homozygosity was significantly associated with $p 14^{A R F}$ and $p 16^{I N K 4 a}$ methylations using the recessive genetic model (Table 5). This association was stronger when comparing the both-methylated and neither-methylated groups.

For the rs10226620, we found that the frequency of minor allele homozygosity was not significantly associated with p1 $14^{A R F}$ methylation, but was significantly associated with p16 ${ }^{I N K 4 a}$ methylation (Table 5). The frequency of minor allele homozygosity was significantly associated with $p 14^{A R F}$ and $p 16^{I N K 4 a}$ methylation when comparing the bothmethylated and neither-methylated groups.

\section{Discussion}

Currently, three major types of human small Maf proteins are recognized (Kataoka et al., 1995). These small Maf proteins have high homology with one another and

Table 5. Association Between $M A F K$ Polymorphisms and $C D K N 2 A$ Methylations

\begin{tabular}{|c|c|c|c|c|c|}
\hline \multirow[b]{2}{*}{ rs4268033 } & \multicolumn{3}{|c|}{ Genotype (n) } & \multirow{2}{*}{$\frac{O R(95 \% C I) ; \mathrm{p}}{\text { GG versus GA + AA }}$} & \multirow{2}{*}{$\frac{O R(95 \% C I) ; p}{\mathrm{GG}+\mathrm{GA} \text { versus AA }}$} \\
\hline & GG & GA & AA & & \\
\hline$p 14^{A R F}$-UM (268) & 124 & 125 & 19 & Reference & Reference \\
\hline$p 14^{A R F}-\mathrm{M}(132)$ & 57 & 58 & 17 & $1.17(0.762-1.80) ; 0.47$ & $1.92(0.953-3.88) ; 0.068$ \\
\hline$p 16^{I N K 4 a}$-UM (288) & 128 & 139 & 21 & Reference & Reference \\
\hline$p 16^{I N K 4 a}-\mathrm{M}(112)$ & 53 & 44 & 15 & $0.856(0.542-1.35) ; 0.50$ & $1.98(0.922-3.95) ; 0.082$ \\
\hline Neither methylated $(n=206)$ & 94 & 98 & 14 & Reference & Reference \\
\hline Both methylated $(n=50)$ & 23 & 17 & 10 & $1.05(0.545-2.04) ; 0.88$ & 3.58 (1.41-9.06); 0.0071 \\
\hline rs 3735656 & TT & $\mathrm{TC}$ & $\mathrm{CC}$ & $\mathrm{TT}$ versus $\mathrm{TC}+\mathrm{CC}$ & $\mathrm{TT}+\mathrm{TC}$ versus CC \\
\hline$p 14^{A R F}$-UM (268) & 106 & 136 & 26 & Reference & Reference \\
\hline$p 14^{A R F}-\mathrm{M}(132)$ & 51 & 57 & 24 & $1.02(0.654-1.58) ; 0.94$ & $1.98(1.07-3.66) ; 0.029$ \\
\hline$p 16^{I N K 4 a}$-UM (288) & 113 & 149 & 26 & Reference & Reference \\
\hline p16 ${ }^{I N K 4 a}-\mathrm{M}(112)$ & 44 & 44 & 24 & $0.870(0.545-1.39) ; 0.56$ & $2.50(1.33-4.68) ; 0.0042$ \\
\hline Unmethylated $(n=206)$ & 80 & 109 & 17 & Reference & Reference \\
\hline Both methylated $(n=50)$ & 18 & 17 & 15 & $1.05(0.529-2.09) ; 0.89$ & 4.49 (1.95-10.4); 0.0004 \\
\hline rs 10226620 & $\mathrm{CC}$ & $\mathrm{CT}$ & TT & $\mathrm{CC}$ versus $\mathrm{CT}+\mathrm{TT}$ & $\mathrm{CC}+\mathrm{CT}$ versus $\mathrm{TT}$ \\
\hline$p 14^{A R F}$-UM (268) & 113 & 125 & 30 & Reference & Reference \\
\hline$p 14^{A R F}-\mathrm{M}(132)$ & 51 & 58 & 23 & $1.14(0.738-1.77) ; 0.55$ & $1.60(0.875-2.91) ; 0.13$ \\
\hline$p 16^{I N K 4 a}-\mathrm{UM}(288)$ & 120 & 139 & 29 & Reference & Reference \\
\hline$p 16^{I N K 4 a}-\mathrm{M}(112)$ & 44 & 44 & 24 & $1.00(0.628-1.59) ; 1.00$ & 2.45 (1.21-4.15); 0.0099 \\
\hline Unmethylated $(n=206)$ & 87 & 98 & 21 & Reference & Reference \\
\hline Both methylated $(n=50)$ & 18 & 17 & 15 & $1.32(0.668-2.61) ; 0.42$ & 3.45 (1.54-7.72); 0.0027 \\
\hline
\end{tabular}

By logistic regression analysis after adjustment for age, gender $($ male $=1)$, and $H$. pylori infection status $($ infected $=1)$. UM, unmethylated; $M$, methylated;. 
transcriptional activity through the formation of a homodimer or heterodimer with other small Maf proteins or with other basic leucine zipper (bZIP) transcription factors (Igarashi et al., 1994). Previous studies using knockout mutant mice have shown that $\mathrm{MafF}^{-1-} / \mathrm{G}^{-1-}$ mice and $\mathrm{MafF}^{-1-} / \mathrm{K}^{-1-}$ mice are viable, whereas $\mathrm{MafG}^{-/-} / \mathrm{K}^{-/-}$was lethal in mice (Onodera et al., 2000; Motohashi et al., 2004). Other studies revealed that induction of the expression of the antioxidant enzyme HO-1 is controlled by the MafK-Bach1 (Broad-Complex, Tramtrack and Bric a brac and Cap'n'collar [CNC] homology 1) system and that the Nrf2MafK heterodimer upregulates HO-1 expression (Sun et al., 2002; Zhang et al., 2006). Thus, MafK appears to play an important role in eliminating the ROS. Moreover, the HapMapJPT population revealed a large number of SNP linkage blocks in the vicinity of the $M A F K$ gene, whereas fewer SNP linkage blocks were found near the $M A F G$ gene. Therefore, we thought that genetic polymorphisms of $M A F K$ might play an essential role in human inflammatory diseases.

All three genetic polymorphisms studied in the current population of 491 subjects met HWE. Moreover, the distributions of the gene polymorphisms rs4268033 and rs 10226620 did not deviate from the distributions of genotypes in the HapMap-CHB + JPT population $(p=0.84$ and 0.55 , respectively), and the distribution of rs3635656 did not deviate from the distribution in the HapMap-JPT population $(p=0.11)$. Therefore, it can safely be stated that the genetic polymorphisms studied in this study are representative of the genetic polymorphisms found in the average Japanese population. We have already reported the association of these three $M A F K$ gene polymorphisms with susceptibility to ulcerative colitis (UC) (Arisawa et al., 2017). In that report, because the presence of homozygous minor alleles of the polymorphisms rs4368033 and rs3735656, which is a tag SNP with two large linkage blocks, was shown to be significantly associated with susceptibility to UC, we thought that the minor allele variants in the $M A F K$ gene polymorphism are of proinflammatory individuals. In this study, the minor alleles of rs3735656 and rs10226620 were significantly associated with the severity of gastric mucosal atrophy according to the results of the dominant genetic model; they were also associated with the $\mathrm{CpG}$ methylation status of $C D K N 2 A$ according to the recessive genetic model results. These data are in general agreement with our previous results.

Few studies have described associations between $M A F K$ polymorphisms and various disorders, and most of those that have been published concerned associations with druginduced hepatic injury (Nanashima et al., 2012; MartínezHernández et al., 2014; Chen et al., 2019). Nanashima et al. (2012) reported that the minor allele of rs4720833 in the same linkage block as rs4268033 increased susceptibility to drug-induced liver injury based on a dominant genetic model, but the minor allele of rs3808337 in the same block as rs3735656 did not increase susceptibility. They also reported that minor alleles of $M A F K$ polymorphisms in this linkage block promoted inflammation. As for gastric carcinogenesis, there is thought to be a sequence of steps from $H$. pylori infection to chronic inflammation of the stomach, gastric mucosal atrophy, accumulation of aberrant genetic $\mathrm{CpG}$ methylation, and finally carcinogenesis (Correa, 1992). Our results indicate that the minor alleles of $M A F K$ are associated with the degree of gastric mucosal atrophy based on the dominant genetic model. The serum PG I/II ratio was also reduced in carriers of minor alleles, indicating that minor alleles were significantly associated not only histologically but also with the extent of atrophic mucosa, because the degree of the decrease in PG I/II ratio serves as an indicator of the extent of gastric mucosal atrophy (Sipponen et al., 2002). In addition, minor alleles were associated with increased methylation of $C D K N 2 A$ based on the recessive genetic model. This might indicate that homozygous mutations have a greater effect on the MafK protein than heterozygous mutations, making subjects with homozygous mutations more likely to advance to the next step of disease development. The strong involvement of polymorphisms at the $3^{\prime}$-UTR of $M A F K$ in this study suggests that these SNPs promote structural changes in $3^{\prime}$-UTR, which subsequently affect the interaction with certain microRNAs.

The mechanism of the involvement of $M A F K$ gene polymorphisms in disease is unclear. One hypothesis is that changes in MafK expression lead to a reduction in the response to ROS or other toxic substances. The small Maf proteins reside in the nucleus and form a dimer with CNCbZIP family proteins such as Bach1 (Fujiwara et al., 1993). Under oxidative stress, the small Maf-Bach1 heterodimer leaves the antioxidant-responsive element and is replaced by the Maf-Nrf2 heterodimer, which binds and induces a group of antioxidant enzymes. Nanashima et al. (2012) speculated that polymorphisms in the 3 -UTR of $M A F K$ induce the expression of MafK that dimerizes with $\mathrm{Nrf} 2$ and/or reduce the expression of MafK that dimerizes with Bach1. This could be the reason polymorphisms in MAFK $3^{\prime}$-UTR appeared to be associated with the severity of atrophic gastritis and CIHM of $C D K N 2 A$ in our study. Another possibility is the result of the effects of $M A F K$ on inflammation and immunity. A previous report showed that overexpression of the MafK protein in $\mathrm{T}$ cells inhibits $\mathrm{T}$ cell proliferation and causes the decreased secretion of interleukin-2 (IL-2; Yoh et al., 2001). Hence, reduced MafK expression might stimulate IL-2 secretion and continued inflammation. Conversely, it has recently been revealed that MafK positively regulates nuclear factor- $\kappa \mathrm{B}(\mathrm{NF}-\kappa \mathrm{B})$ expression (Hwang et al., 2013), suggesting that the overexpression of MafK might induce inflammation through increased $\mathrm{NF}-\kappa \mathrm{B}$ expression. In any case, further studies on the protein expression of $M A F K$ gene polymorphisms are necessary.

In this study, we demonstrated a significant association between $M A F K$ polymorphisms and the CIHM status. Both p $14^{A R F}$ and p16 $16^{I N K 4 a}$ regulate the cell cycle negatively through the p53 and retinoblastoma protein pathways, respectively (Rizos et al., 2000; Tannapfel et al., 2001). Therefore, the possibility that the $\mathrm{CpG}$ methylation of both these genes might be directly involved in the development of gastric cancer cannot be excluded. Conversely, $\mathrm{CpG}$ methylation of $C D K N 2 A$ has been reported relatively early in chronic inflammatory mucosa in non-neoplastic areas (Maekita et al., 2006; Tahara et al., 2007; Niwa et al., 2010). CIHM and non-CpG hypomethylation have been observed in human cancers, which are known as changes in global DNA methylation patterns ( $\mathrm{Li}$ and Chen, 2013). It is possible that the $\mathrm{CpG}$ methylation of $C D K N 2 A$ investigated in this study is only part of this early change in global DNA methylation patterns. At any rate, the involvement of $M A F K$ gene polymorphisms in gastric cancer development is of interest and is a subject for future study. 


\section{Conclusion}

In conclusion, carrying the minor alleles of various $M A F K$ polymorphisms, especially those located in the $3^{\prime}$-UTR, is associated with a higher risk of severe gastric mucosal atrophy, and $\mathrm{CpG}$ methylation of $C D K N 2 A$ may occur in homozygous minor alleles of these polymorphisms.

\section{Acknowledgment}

We would like to thank Prof. Yasuhito Ishigaki for proofreading this article.

\section{Author Disclosure Statement}

No competing financial interests exist.

\section{Funding Information}

No funding was received for this article.

\section{References}

Arisawa T, Nakamura M, Otsuka T, et al. (2017) Genetic polymorphisms of MAFK, encoding a small Maf protein, are associated with susceptibility to ulcerative colitis in Japan. World J Gastroenterol 23:5364-5370.

Arisawa T, Tahara T, Shibata T, et al. (2007) The relationship between Helicobacter pylori infection and promoter polymorphism of the Nrf2 gene in chronic gastritis. Int J Mol Med 19:143-148.

Arisawa T, Tahara T, Shibata T, et al. (2008) The influence of promoter polymorphism of nuclear factor-erythroid 2-related factor 2 gene on the aberrant DNA methylation in gastric epithelium. Oncol Rep 19:211-216.

Bray F, Ferlay J, Soerjomataram I, et al. (2018) Global cancer statistics 2018: GLOBOCAN estimates of incidence and mortality worldwide for 36 cancers in 185 countries. CA Cancer J Clin 68:394-424.

Chen S, Pan H, Chen Y, et al. (2019) Association between genetic polymorphisms of NRF2, KEAP1, MAFF, MAFK and anti-tuberculosis drug-induced liver injury: a nested casecontrol study. Sci Rep 9:14311.

Correa P (1992) Human gastric carcinogenesis: a multistep and multifactorial process-First American Cancer Society Award Lecture on Cancer Epidemiology and Prevention. Cancer Res 52: 6735-6740.

Dixon MF, Genta RM, Yardley JH et al. (1996) Classification and grading of gastritis. The updated Sydney system. International Workshop on the Histopathology of Gastritis, Houston 1994. Am J Surg Pathol 20:1161-1181.

Fujiwara KT, Kataoka K, Nishizawa M (1993) Two new members of the maf oncogene family, mafK and mafF, encode nuclear b-Zip proteins lacking putative trans-activator domain. Oncogene 8:2371-2380.

Hwang YJ, Lee EW, Song J, et al. (2013) MafK positively regulates $\mathrm{NF}-\kappa \mathrm{B}$ activity by enhancing CBP-mediated $\mathrm{p} 65$ acetylation. Sci Rep 3:3242.

Igarashi K, Kataoka K, Itoh K, et al. (1994) Regulation of transcription by dimerization of erythroid factor NF-E2 p45 with small Maf proteins. Nature 367:568-572.

Ishii T, Itoh K, Takahashi S, et al. (2000) Transcription factor Nrf2 coordinately regulates a group of oxidative stressinducible genes in macrophages. J Biol Chem 275:1602316029.
Itoh K, Chiba T, Takahashi S, et al. (1997) An Nrf2/small Maf heterodimer mediates the induction of phase II detoxifying enzyme genes through antioxidant response elements. Biochem Biophys Res Commun 236:313-322.

Jones PA, Baylin SB (2002) The fundamental role of epigenetic events in cancer. Nat Rev Genet 3:415-428.

Kataoka K, Igarashi K, Itoh K, et al. (1995) Small Maf proteins heterodimerize with Fos and may act as competitive repressors of the NF-E2 transcription factor. Mol Cell Biol 15: 2180-2190.

Li W, Chen BF (2013) Aberrant DNA methylation in human cancers. J Huazhong Univ Sci Technol Med Sci 33: 798-804.

Maekita T, Nakazawa K, Mihara M, et al. (2006) High levels of aberrant DNA methylation in Helicobacter pylori-infected gastric mucosae and its possible association with gastric cancer risk. Clin Cancer Res 12 Pt 1:989-995.

Martínez-Hernández A, Gutierrez-Malacatt H, Carrillo-Sánchez $\mathrm{K}$, et al. (2014) Small MAF genes variants and chronic myeloid leukemia. Eur J Haematol 92:35-41.

Motohashi H, Katsuoka F, Engel JD, et al. (2004) Small Maf proteins serve as transcriptional cofactors for keratinocyte differentiation in the Keap1-Nrf2 regulatory pathway. Proc Natl Acad Sci U S A 101:6379-6384.

Naito Y, Yoshikawa T (2002) Molecular and cellular mechanisms involved in Helicobacter pylori-induced inflammation and oxidative stress. Free Radic Biol Med 33 323336.

Nanashima K, Mawatari T, Tahara N, et al. (2012) Genetic variants in antioxidant pathway: risk factors for hepatotoxicity in tuberculosis patients. Tuberculosis (Edinb) 92:253259.

Niwa T, Tsukamoto T, Toyoda T, et al. (2010) Inflammatory processes triggered by Helicobacter pylori infection cause aberrant DNA methylation in gastric epithelial cells. Cancer Res 70:1430-1440.

Onodera K, Shavit JA, Motohashi H, et al. (2000) Perinatal synthetic lethality and hematopoietic defects in compound mafG::mafK mutant mice. EMBO J 19:1335-1345.

Ozasa K, Kurata JH, Higashi A, et al. (1999) Helicobacter pylori infection and atrophic gastritis: a nested case-control study in a rural town in Japan. Dig Dis Sci 44:253-256.

Plummer M, de Martel C, Vignat J, et al. (2016) Global burden of cancers attributable to infections in 2012: a synthetic analysis. Lancet Glob Health 4:e609-e616.

Rizos H, Darmanian AP, Mann GJ, et al. (2000) Two arginine rich domains in the p14ARF tumour suppressor mediate nucleolar localization. Oncogene 19:2978-2985.

Sipponen P, Härkönen M, Alanko A, et al. (2002) Diagnosis of atrophic gastritis from a serum sample. Clin Lab 48:505-515.

Sun J, Hoshino H, Takaku K, et al. (2002) Hemoprotein Bach1 regulates enhancer availability of heme oxygenase-1 gene. EMBO J 21:5216-5224.

Tahara T, Arisawa T, Shibata T, et al. (2007) Risk prediction of gastric cancer by analysis of aberrant DNA methylation in non-neoplastic gastric epithelium. Digestion 75:54-61.

Tahara T, Arisawa T, Shibata T, et al. (2009) Increased number of methylated $\mathrm{CpG}$ islands correlates with Helicobacter pylori infection, histological and serological severity of chronic gastritis. Eur J Gastroenterol Hepatol 21:613-619.

Tahara T, Shibata T, Nakamura M, et al. (2011) Polymorphisms of DNA repair and xenobiotic genes predispose to $\mathrm{CpG}$ island methylation in non-neoplastic gastric mucosa. Helicobacter 16:99-106. 
Tan P, Yeoh KG (2015) Genetics and molecular pathogenesis of gastric adenocarcinoma. Gastroenterology 149:1153-1162.

Tannapfel A, Busse C, Weinans L, et al. (2001) INK4a-ARF alterations and p53 mutations in hepatocellular carcinomas. Oncogene 20:7104-7109.

Uemura N, Okamoto S, Yamamoto S, et al. (2001) Helicobacter pylori infection and the development of gastric cancer. N Engl J Med 345:784-789.

Watanabe Y, Kurata JH, Mizuno S, et al. (1997) Helicobacter pylori infection and gastric cancer. A nested case-control study in a rural area of Japan. Dig Dis Sci 42:1383-1387.

Yoh K, Sugawara T, Motohashi H, et al. (2001) Transgenic over-expression of MafK suppresses $\mathrm{T}$ cell proliferation and function in vivo. Genes Cells 6:1055-1066.
Zhang J, Ohta T, Maruyama A, et al. (2006) BRG1 interacts with Nrf2 to selectively mediate HO-1 induction in response to oxidative stress. Mol Cell Biol 26:7942-7952.

Address correspondence to: Tomiyasu Arisawa, MD Department of Gastroenterology Kanazawa Medical University 1-1, Daigaku Uchinada-machi Ishikawa 920-0293 Japan

E-mail: tarisawa@kanazawa-med.ac.jp 